\title{
Highly accurate dating of micrometre-scale baddeleyite domains through combined focused ion beam extraction and U-Pb thermal ionization mass spectrometry (FIB-TIMS)
}

\author{
Lee F. White ${ }^{1,2}$, Kimberly T. Tait ${ }^{1,2}$, Sandra L. Kamo ${ }^{2,3}$, Desmond E. Moser ${ }^{4}$, and James R. Darling ${ }^{5}$ \\ ${ }^{1}$ Department of Natural History, Royal Ontario Museum, Toronto, Ontario, M5S 2C6, Canada \\ ${ }^{2}$ Department of Earth Sciences, University of Toronto, Toronto, Ontario, M5S 3B1, Canada \\ ${ }^{3}$ Jack Satterly Geochronology Laboratory, University of Toronto, Toronto, Ontario, M5S 3B1, Canada \\ ${ }^{4}$ Department of Earth Sciences, University of Western Ontario, London, Ontario, Canada \\ ${ }^{5}$ School of the Environment, Geography and Geosciences, University of Portsmouth, Portsmouth, PO1 3QL, UK
}

Correspondence: Lee F. White (lwhite@ rom.on.ca)

Received: 14 November 2019 - Discussion started: 29 November 2019

Revised: 29 April 2020 - Accepted: 11 May 2020 - Published: 7 July 2020

\begin{abstract}
Baddeleyite is a powerful chronometer of mafic magmatic and meteorite impact processes. Precise and accurate $\mathrm{U}-\mathrm{Pb}$ ages can be determined from single grains by isotope dilution thermal ionization mass spectrometry (IDTIMS), but this requires disaggregation of the host rock for grain isolation and dissolution. As a result, the technique is rarely applied to precious samples with limited availability (such as lunar, Martian, and asteroidal meteorites and returned samples) or samples containing small baddeleyite grains that cannot readily be isolated by conventional mineral separation techniques. Here, we use focused ion beam (FIB) techniques, utilizing both $\mathrm{Xe}^{+}$plasma and $\mathrm{Ga}^{+}$ion sources, to liberate baddeleyite subdomains directly, allowing their extraction for ID-TIMS dating. We have analysed the $\mathrm{U}-\mathrm{Pb}$ isotope systematics of domains ranging between 200 and $10 \mu \mathrm{m}$ in length and from 5 to $\leq 0.1 \mu \mathrm{g}$ in mass. In total, six domains of Phalaborwa baddeleyite extracted using a $\mathrm{Xe}^{+}$plasma FIB (pFIB) yield a weighted mean ${ }^{207} \mathrm{~Pb} /{ }^{206} \mathrm{~Pb}$ age of $2060.1 \pm 2.5 \mathrm{Ma}(0.12 \%$; all uncertainties $2 \sigma$ ), within uncertainty of reference values. The smallest extracted domain (ca. $10 \times 15 \times 10 \mu \mathrm{m}$ ) yields an internal ${ }^{207} \mathrm{~Pb} /{ }^{206} \mathrm{~Pb}$ age uncertainty of $\pm 0.37 \%$. Comparable control on cutting is achieved using a $\mathrm{Ga}^{+}$-source FIB instrument, though the slower speed of cutting limits potential application to larger grains. While the U-Pb data are between $0.5 \%$ and $13.6 \%$ discordant, the extent of discordance does not correlate with the ratio of material to ion-milled surface
\end{abstract}

area, and results generate an accurate upper-intercept age in U-Pb concordia space of $2060.20 \pm 0.91 \mathrm{Ma}(0.044 \%)$. Thus, we confirm the natural $\mathrm{U}-\mathrm{Pb}$ variation and discordance within the Phalaborwa baddeleyite population observed with other geochronological techniques. Our results demonstrate the FIB-TIMS technique to be a powerful tool for highly accurate in situ ${ }^{207} \mathrm{~Pb} /{ }^{206} \mathrm{~Pb}$ (and potentially $\mathrm{U}-\mathrm{Pb}$ in concordant materials) age analysis, allowing dating of a wide variety of targets and processes newly accessible to geochronology.

\section{Introduction}

The generation of high-precision chronological data is a cornerstone of the Earth and planetary sciences, providing an absolute measurement on which to anchor relative observations of geological time (e.g. Gradstein et al., 2004). The most precise radiogenic isotopic ratios (e.g. U-Th- $\mathrm{Pb}, \mathrm{Sm}-\mathrm{Nd}$, $\mathrm{Rb}-\mathrm{Sr}$ ) are generated using isotope dilution thermal ionization mass spectrometry (ID-TIMS; Parrish and Noble, 2003), which has been used to measure the timing of solar system formation (Amelin et al., 2002), initial differentiation of the Moon (Barboni et al., 2017), and the timing of crustal formation on Mars (Bouvier et al., 2018), often with internal age uncertainties on the order of $\sim 0.1 \% 2 \sigma$. In particular, $\mathrm{U}-\mathrm{Pb}$ isotopic measurements of the accessory minerals zircon $\left(\mathrm{ZrSiO}_{4}\right)$ and baddeleyite $\left(\mathrm{ZrO}_{2}\right)$ by ID-TIMS allows for 
direct, high-precision dating of magmatic, metamorphic, and shock metamorphic events (e.g. Krogh et al., 1987; Parrish and Noble, 2002; Bouvier et al., 2018).

To attain the high level of precision and accuracy offered by ID-TIMS, desired mineral grains must be isolated from their host rock using crushing and sieving techniques or electric pulse disaggregation before separation based on density, magnetic, and optical properties of the target mineral phase (e.g. Söderlund and Johansson, 2002). As a result, the analysed grains preserve no evidence of their petrological or mineralogical context and are challenging to characterize prior to dating, which makes the accurate interpretation of $\mathrm{U}_{-}$ $\mathrm{Th}-\mathrm{Pb}$ ages in samples with complex thermal, metamorphic and deformational histories highly challenging (e.g. Krogh et al., 1993a, b; Parrish and Noble, 2002; Bouvier et al., 2018). In addition, the small grain size (commonly $<50 \mu \mathrm{m}$ ) and bladed nature of individual baddeleyite crystals makes clean separation of target grains time consuming and highly challenging (e.g. Söderlund and Johansson, 2002). Though grains can be chemically or physically abraded to remove potentially discordant crystallographic domains (Krogh, 1982; Rioux et al., 2010) or physically broken to yield isolated fragments (Amelin, 1998), ID-TIMS is incapable of separating crystallographic domains of potentially different ages, such as micrometre-scale recrystallized or altered domains in shocked minerals which may record disturbed $\mathrm{U}-\mathrm{Pb}$ isotope reservoirs (Cavosie et al., 2015; White et al., 2017a, b). These realities mean that, although ID-TIMS is the method that can deliver the most accurate and precise isotopic data, it has historically remained challenging to impossible to apply it to rare meteoritic or returned planetary materials or mineral targets located within thin sections. Developing the capability for highly targeted extraction of micrometre-scale domains for ID-TIMS would be a powerful advancement. It would permit the generation of relatively highly precise radio-isotopic ages from microstructurally and chemically characterized grains (Moser et al., 2011, 2013; Darling et al., 2016). In effect, this would enable in situ dating using petrological and mineralogical evidence of crystallization and/or metamorphic history, information that is often critical to accurately interpreting isotopic ages.

Focused ion beam (FIB) technologies are a staple of the material sciences, most commonly used to fabricate and analyse nanomaterials (Matsui et al., 2000; Schaffer et al., 2012). Within the Earth and planetary sciences, FIBs have principally been used to prepare thin foils for analysis of materials by transmission electron microscopy (TEM), which requires a sample to be electron transparent (Heaney et al., 2001), and the preparation of microtip specimens for atom probe tomography (e.g. Reddy et al., 2016). Although $\mathrm{Ga}^{+}$source FIBs are the most common, the linear relationship between beam current and spot size prevents operation of the instrument at high currents $(>20 \mathrm{nA})$, limiting the rate (and thus volume) of material removal to the tens of micrometres in a single-day session. Options for the removal of larger masses require higher energy; for example, laser cutting allows extraction of millimetre-scale sections of material but induces deeper and more severe damage to the milled surface (Echlin et al., 2012) and in the case of geological materials may result in localized fractionation of target elements and isotopes comparable to heating effects seen in laser ablation inductively coupled plasma mass spectrometry (LAICP-MS; e.g. Košler et al., 2005; Ibanez-Mejia et al., 2014). Such side effects are not induced by micro-drill extraction of target phases (e.g. Paquette et al., 2004), but the spatial resolution offered by such an approach is incapable of isolating exceptionally small $(<50 \mu \mathrm{m})$ domains, such as meteoritic micro-baddeleyite (Herd et al., 2017).

Recent advances in FIB technologies have significantly broadened the range of ion beam chemistries and source types, the most recent being the magnetically enhanced, inductively coupled xenon $\left(\mathrm{Xe}^{+}\right)$plasma ion source (Bassim et al., 2014). While a $\mathrm{Ga}^{+}$liquid metal ion source (LMIS) FIB loses spatial resolution at higher currents $(I)$ due to spherical aberration resulting in a non-Gaussian beam shape with large tails (Smith et al., 2006; Bassim et al., 2014), the $\mathrm{Xe}^{+}$ICP source remains stable beyond $\sim 60 \mathrm{nA}$. As a result, a finer spot size can be achieved for the same focussing optics using a $\mathrm{Xe}^{+} \mathrm{pFIB}$, while the superior angular intensity allows for high current milling as the effects of spherical aberration are not realized (Smith et al., 2006). This makes the attainment of currents in the microamp range possible with a $\mathrm{Xe}^{+}$ pFIB, which cannot be achieved with a $\mathrm{Ga}^{+}$LMIS instrument whilst retaining a focused beam (Fig. 1). Another important benefit of the $\mathrm{Xe}^{+} \mathrm{pFIB}$ is a direct result of the larger ionic size of $\mathrm{Xe}^{+}$compared to $\mathrm{Ga}^{+}$(e.g. Yuan et al., 2017), which results in more atoms of material being ejected from the target per incident ion and yields a higher removal rate. Though sputtering rates are typically on the order of $10 \%-$ $30 \%$ higher for $\mathrm{Xe}^{+}$compared to $\mathrm{Ga}^{+}, \mathrm{Cu}(\sim 300 \%$ higher $)$ and $\mathrm{Si}(30 \%-50 \%$ higher) demonstrate notably higher sputter rates per coulomb when exposed to a $\mathrm{Xe}^{+}$ion beam (Ziegler et al., 1985). The larger ionic size of $\mathrm{Xe}^{+}$also results in a shallower depth of ion penetration and resulting damage to the target material; for example, the penetration of $\mathrm{Ga}^{+}$and $\mathrm{Xe}^{+}$in $\mathrm{Si}$ is 24 and $28 \mathrm{~nm}$, respectively at $30 \mathrm{kV}$ (Ziegler et al., 1985; Burnett et al., 2016). However, the effect of this interaction, which often results in amorphization of the surface layer exposed to the ion beam, on trace element distribution and mobility is poorly constrained. For example, the effect on $\mathrm{U}$ and $\mathrm{Pb}$ mobility is unknown. In this study, we analyse multiple samples of the Phalaborwa U-Pb baddeleyite reference material, which have been extracted in situ via $\mathrm{Ga}^{+} \mathrm{FIB}, \mathrm{Xe}^{+} \mathrm{pFIB}$, and by mechanical (non-FIB) fragmentation to test for structural damage, heating, and ion implantation during FIB exposure, establishing a new approach to microsampling for high-precision ID-TIMS analysis and demonstrating the potential for $\mathrm{Xe}^{+}$FIB techniques to extract grains from thin sections. 


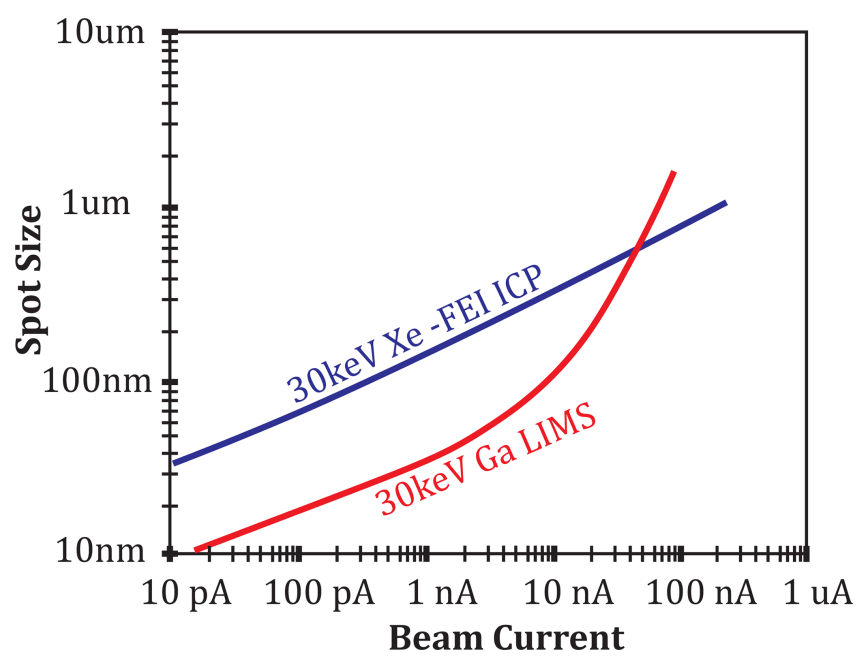

Figure 1. Spot size versus beam current for $\mathrm{Xe}^{+}$- and $\mathrm{Ga}^{+}$-source focused ion beam (FIB) instruments. At higher beam currents $(>10 \mathrm{nA})$ the spot size generated by the liquid-metal-ion-source (LMIS) $\mathrm{Ga}^{+}$FIB exponentially increases due to spherical aberration, limiting the energy that can be applied during milling. The inductively coupled Xe-pFIB source remains stable at higher currents, yielding a linear increase in spot size with beam current and allowing higher energies to be applied without sacrificing spatial precision. This opens the door to larger-scale (millimetre) milling experiments, such as extracting whole mineral phases from thin section or grain mount. Adapted from Burnett et al. (2016).

\subsection{Sample and methodology}

Originally sampled from the Phalaborwa complex (a composite intrusion of cumulate clinopyroxenites related to pulsed carbonatite magma emplacement) in South Africa, baddeleyite grains from the locality are often used as a reference material in U-Th- $\mathrm{Pb}$ studies (Reischmann, 1995; Heaman, 2009; Schmitt et al., 2010). A single large crystal of Phalaborwa baddeleyite was acquired from the same sample at the Royal Ontario Museum as studied by Heaman (2009), which undertook 68 ID-TIMS measurements of 2 to $384 \mathrm{mg}$ fragments of this material. These fragments are variable in $U$ concentration (51-2124 ppm), and the majority of U-Pb analyses from Heaman (2009) are $<1 \%$ discordant, although individual analyses are up to $10 \%$ discordant. A precise weighted mean ${ }^{207} \mathrm{~Pb} /{ }^{206} \mathrm{~Pb}$ age from 56 baddeleyite analyses of $2059.70 \pm 0.35 \mathrm{Ma}$ from that study, though with significant scatter (mean square weighted deviation $(\mathrm{MSWD})=12)$, is taken as the best measure of the crystallization age. Variations in $\mathrm{U}$ content and $\mathrm{U}-\mathrm{Pb}$ age have also been reported during high-spatial-resolution isotopic analyses of Phalaborwa, such as depth-profiling laser ablation inductively coupled plasma mass spectrometry (LA-ICP-MS) (Ibanez-Mejia et al., 2014). During 326 small volume LAICP-MS analyses of Phalaborwa baddeleyite, U concentration (87-1478 ppm) and percentage discordance $(<13.7 \%)$ vary substantially, while the majority $(77 \%)$ of $\mathrm{U}-\mathrm{Pb}$ anal- yses are $>1 \%$ discordant outside of uncertainty (IbanezMejia et al., 2014). Notably, 30 of these analyses are highly discordant ( $>5 \%$ discordance).

\subsection{Focused ion beam (FIB) extraction of target domains}

A large $(\sim 5 \mathrm{~cm})$ grain of Phalaborwa baddeleyite was taken from the mineralogy collection at the Royal Ontario Museum, Toronto, Canada, for use in this study (accession number M37144). The grain was mounted in epoxy and polished to expose the surface of the grain using 6,1 , and $0.5 \mu \mathrm{m}$ grit diamond paste. The epoxy mount was secured to a scanning electron microscope (SEM) stub and coated with a $15 \mathrm{~nm}$ thick carbon coat prior to imaging and FIB work. A Thermo Scientific Helios G4 UXe DualBeam pFIB-SEM at the Canadian Centre for Electron Microscopy (CCEM) at McMaster University, Canada, and a Hitachi NB5000 Ga FIB-SEM at the Ontario Centre for the Characterisation of Advanced Materials (OCCAM) at the University of Toronto, Canada, were used in this study.

The Xe pFIB was operated at $30 \mathrm{kV}, 2.5 \mu \mathrm{A}$ for the largest cuts, facilitating the extraction of a $100 \mu \mathrm{m} \times 100 \mu \mathrm{m} \times 100 \mu \mathrm{m}$ cube domain of baddeleyite in $32 \mathrm{~min}$ and two $200 \mu \mathrm{m} \times$ $50 \mu \mathrm{m} \times 30 \mu \mathrm{m}$ rectangular domains in $21 \mathrm{~min}$ each. Two small $(5 \mu \mathrm{m} \times 15 \mu \mathrm{m} \times 10 \mu \mathrm{m})$ cuboids of baddeleyite were completely isolated by $2 \mathrm{~min}$ of Xe-pFIB exposure. The Ga FIB was operated at $40 \mathrm{kV}$ and $>50 \mathrm{nA}$ (estimated current from previous calibration), taking $2 \mathrm{~h}$ to isolate a $50 \mu \mathrm{m} \times$ $50 \mu \mathrm{m} \times 50 \mu \mathrm{m}$ cube domain. In all scenarios a small amount of material $(<5 \mu \mathrm{m}$ wide) was left to anchor the isolated domain to the host mount (Fig. 2). This allowed transportation of the grain mount to the Jack Satterly Geochronology Laboratory for extraction without the use of platinum or tungsten weld, which may contain unconstrained levels of common $\mathrm{Pb}$. The grain mount was placed in a large petri dish before being entirely submerged in ethanol. Fine-tipped tweezers and custom pipettes (made within the Jack Satterly Geochronology Laboratory) were used to physically detach the focused-ion-beamed material under an optical microscope, where it became suspended in the alcohol layer before being transferred to a separate dish for imaging. Following extraction, the tip of one of the $200 \mu \mathrm{m} \times 50 \mu \mathrm{m} \times 30 \mu \mathrm{m}$ rectangles was physically broken to produce two smaller $(<15 \mu \mathrm{m})$ domains consisting of outer surface areas that have been both focused-ion-beamed and not focused-ionbeamed. Extraction of FIB'ed domains was augmented by gouging six chips ( $200 \mu \mathrm{m}$ to $3 \mathrm{~mm}$ in size) of material from the same mounted grain to test the larger-scale homogeneity of the target material, which were separated into two aliquots, and two smaller grains separated and supplied as an existing $\mathrm{U}-\mathrm{Th}-\mathrm{Pb}$ reference material were also analysed. In total, 12 TIMS analyses are incorporated into this study, including two whole $(<40 \mu \mathrm{m})$ baddeleyite grains and 10 subsampled domains of the large mounted grain - two aliquots of material 
physically carved out with no FIB exposure, one subdomain with Ga-FIB extraction, and seven using Xe-pFIB extraction.

\section{$1.3 \mathrm{U}-\mathrm{Pb}$ thermal ionization mass spectrometry (TIMS)}

$\mathrm{U}-\mathrm{Pb}$ geochronology was conducted at the Jack Satterly Geochronology Laboratory, Department of Earth Sciences, at the University of Toronto. Grain weights were estimated from photomicrographs, aided by known size dimensions of grains from FIB preparation. The grains were cleaned in room temperature $8 \mathrm{~N} \mathrm{HNO}_{3}$ on parafilm using a micropipette before being loaded into dissolution vessels with a mixed ${ }^{205} \mathrm{~Pb}-{ }^{235} \mathrm{U}$ isotopic tracer solution. Baddeleyite was dissolved using $\sim 0.10 \mathrm{~mL}$ of concentrated hydrofluoric acid (HF) and $\sim 0.02 \mathrm{~mL}$ of $8 \mathrm{~N}$ nitric acid $\left(\mathrm{HNO}_{3}\right)$ at $200^{\circ} \mathrm{C}$ (Krogh, 1973) for up to $5 \mathrm{~d}$, then dried to a precipitate and redissolved in $\sim 0.15 \mathrm{~mL}$ of $3 \mathrm{~N}$ hydrochloric acid $(\mathrm{HCl})$. Uranium and lead were isolated from the solutions using anion exchange chromatography, dried in dilute phosphoric acid $\left(\mathrm{H}_{3} \mathrm{PO}_{4}\right)$, and deposited onto outgassed rhenium filaments with silica gel (Gerstenberger and Haase, 1997). U and $\mathrm{Pb}$ were analysed with a VG M354 mass spectrometer in dynamic mode with a Daly pulse-counting system. The dead time of the Daly measuring system for $\mathrm{Pb}$ and $\mathrm{U}$ was 16.5 and $14.5 \mathrm{~ns}$, respectively, determined using standard reference materials 982 and U500, respectively. The mass discrimination correction for the Daly detector is constant at $0.05 \%$ per atomic mass unit. Thermal mass fractionation was corrected using $0.1 \%$ per atomic mass unit for both $\mathrm{Pb}$ and $\mathrm{U}$. Given the apparent pristine nature of the FIB-extracted baddeleyite domains, the total common $\mathrm{Pb}$ in each baddeleyite analyses was attributed to laboratory $\mathrm{Pb}$ (corrected using an isotopic composition of ${ }^{206} \mathrm{~Pb} /{ }^{204} \mathrm{~Pb}$ of $18.49 \pm 4.0 \%,{ }^{207} \mathrm{~Pb} /{ }^{204} \mathrm{~Pb}$ of $15.59 \pm 4.0 \%$, and ${ }^{208} \mathrm{~Pb} /{ }^{204} \mathrm{~Pb}$ of $39.36 \pm 4.0 \% ; 2 \sigma$ uncertainties), and thus no correction for initial common $\mathrm{Pb}$ from geological sources was made. Routine testing indicates that laboratory blanks for $\mathrm{Pb}$ and $\mathrm{U}$ are usually less than 0.5 and $0.01 \mathrm{pg}$, respectively. Corrections to the ${ }^{206} \mathrm{~Pb} /{ }^{238} \mathrm{U}$ and ${ }^{207} \mathrm{~Pb} /{ }^{206} \mathrm{~Pb}$ ages for initial ${ }^{230} \mathrm{Th}$ disequilibrium have been made assuming a $\mathrm{Th} / \mathrm{U}$ ratio in the magma of 4.2 , based on assumed crustal average values. Decay constants are those of Jaffey et al. (1971) ${ }^{238} \mathrm{U}$ and ${ }^{235} \mathrm{U}$ are $1.55125 \times 10^{-10}$ and $9.8485 \times 10^{-10} \mathrm{yr}^{-1}$, respectively). A U isotopic composition of 137.818 was used (Hiess et al., 2012). All age errors quoted in the text and tables and error ellipses in the concordia diagram are given at $2 \sigma$.

\section{Results}

In total, 11 TIMS analyses were conducted on grains and subdomains of the Phalaborwa baddeleyite, with one sample extracted by $\mathrm{Ga}^{+}$FIB, six using the $\mathrm{Xe}^{+}$pFIB, two with no exposure to the FIB instruments, and two entirely separate whole grains. A summary of the $\mathrm{U}-\mathrm{Pb}$ isotopic data is presented in Table 1 . U concentrations vary widely

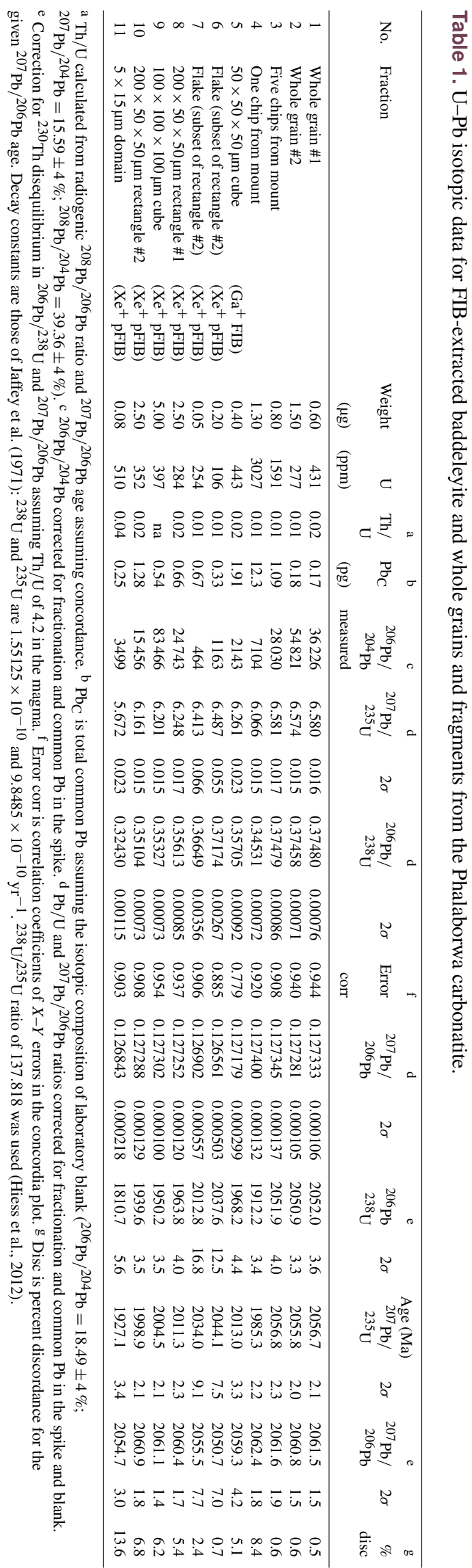

https://doi.org/10.5194/gchron-2-177-2020 


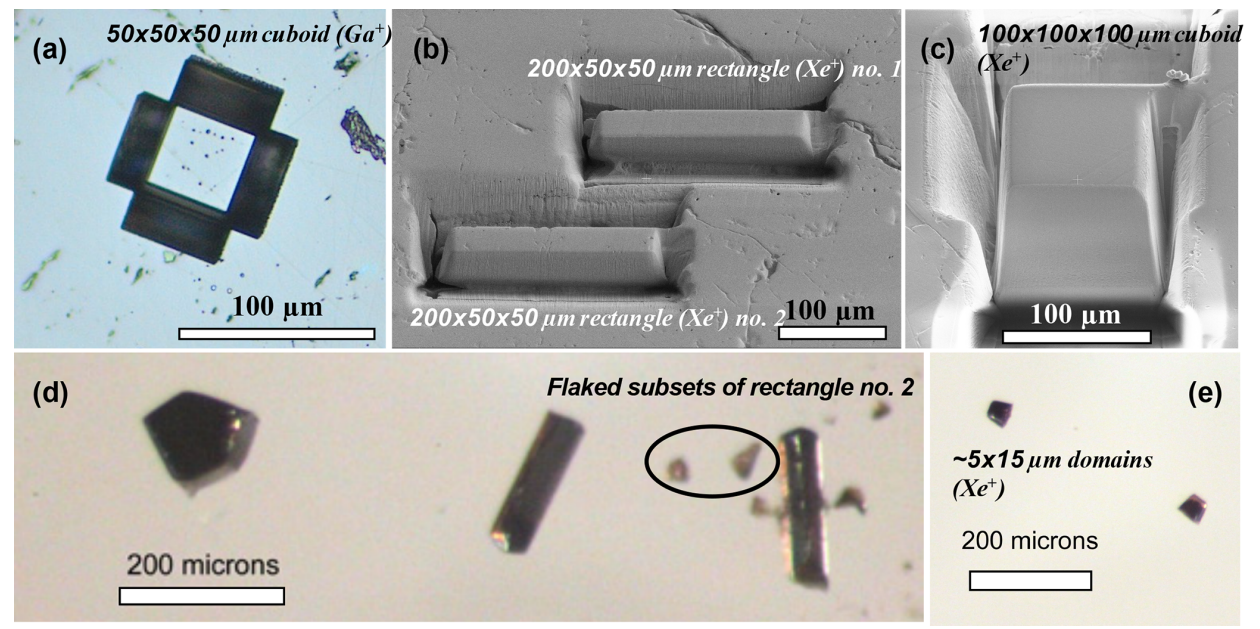

Figure 2. Optical microscopy and secondary electron (SE) imaging of isolated baddeleyite domains in Phalaborwa baddeleyite mount. The small amount of material left to anchor the domains $(\mathbf{a}-\mathbf{c})$ is critical in transporting the mount without losing material and in ensuring easy extraction without the need for tungsten weld or complicated and time-consuming micromanipulator usage. Once released from the grain mount, samples can be broken into further subsamples (d) and extensively imaged (e). All of the FIB-extracted samples used for TIMS analyses, as denoted in Table 1 , are imaged here.

between 106 and $3027 \mathrm{ppm}$, in agreement with published values for Phalaborwa baddeleyite (Heaman, 2009; IbanezMejia et al., 2014; Reinhard et al., 2017), indicative of highly variable $\mathrm{U}$ concentrations within individual grains of the Phalaborwa baddeleyite (Ibanez-Mejia et al., 2014; Reinhard et al., 2017).

The total amount of common $\mathrm{Pb}$ in several of our $\mathrm{U}_{-}$ $\mathrm{Pb}$ analyses exceeded the estimated $\mathrm{Pb}$ procedural blank of $0.5 \mathrm{pg}$. All initial common $\mathrm{Pb}$ in our analytical data was corrected using the reported laboratory blank isotopic composition under the assumption that common $\mathrm{Pb}$ was introduced during laboratory procedures. Although no microinclusions or fracture-hosted alteration zones (that may contain $\mathrm{Pb}$ ) were observed using an SEM or optical microscope, it is possible that measured common $\mathrm{Pb}$ is geological in origin. To test the impact of our common Pb selection we conducted sensitivity tests for three of our results that contain the highest amounts of total common $\mathrm{Pb}$ (analyses 4, 5, 10, Table 1). These show that by applying model-based corrections to the initial common $\mathrm{Pb}$ above, our assumed procedural blank has a negligible effect on the ${ }^{207} \mathrm{~Pb} /{ }^{206} \mathrm{~Pb}$ weighted mean age of the 11 analyses. Using a crustal $\mathrm{Pb}$ isotopic composition (Stacey and Kramers, 1975) and mantle $\mathrm{Pb}$ isotopic composition $\left({ }^{206} \mathrm{~Pb} /{ }^{204} \mathrm{~Pb}\right.$ of $14.624,{ }^{207} \mathrm{~Pb} /{ }^{204} \mathrm{~Pb}$ of 15.038 ) produced age offsets of $0.0044 \%$ and $0.0019 \%$, respectively (i.e. from a mean of $2060.14 \pm 0.88 \mathrm{Ma}, n=11$, to $2060.05 \pm 0.81$ and $2060.18 \pm 0.89 \mathrm{Ma}$, respectively).

Two separate $\sim 30 \mu \mathrm{m}$ fragments, independent of the large grain embedded for FIB work, yield near-concordant results with uncertainties on the order of $\pm 0.07 \% 2 \sigma$ (analyses $1-2$, Table 1$)$. Two larger $(\sim 100 \mu \mathrm{m})$ domains physically broken out of the baddeleyite mounted in epoxy give sim- ilar ${ }^{207} \mathrm{~Pb} /{ }^{206} \mathrm{~Pb}$ ages of 2060.9 and $2061.6 \mathrm{Ma}( \pm 0.09 \%)$, though display $<8.4 \%$ discordance in the measured $\mathrm{U}-\mathrm{Pb}$ systematics (with a youngest ${ }^{206} \mathrm{~Pb} /{ }^{238} \mathrm{U}$ age of $1912 \mathrm{Ma}$; analyses 3-4; Table 1).

All domains extracted by FIB (both $\mathrm{Ga}^{+}$and $\mathrm{Xe}^{+}$source) yield high-precision ${ }^{207} \mathrm{~Pb} /{ }^{206} \mathrm{~Pb}$ ages $(0.07 \%-0.4 \%)$ that are in agreement with published TIMS and single-shot laser ablation inductively coupled plasma mass spectrometry (SSLA-ICP-MS) values (Heaman, 2009; Ibanez-Mejia et al., 2014). This includes a small flake (analysis 7; Table 1) containing as little as $\sim 4.5 \mathrm{pg}$ of $\mathrm{Pb}$. However, all data points, aside from the two whole grains and five chips from the mount (analyses 1-3; Table 1), are discordant (Fig. 3). The most discordant analysis (13.6\% discordant, ${ }^{206} \mathrm{~Pb} /{ }^{238} \mathrm{U}$ age of $1811 \mathrm{Ma})$ was generated by the smallest $(5 \times 15 \mu \mathrm{m})$ domain isolated by Xe pFIB (analysis 11, Table 1), though there is otherwise no correlation between surface area exposed to the FIB and severity of discordance. This is supported by the observed age overlap between the $50 \mu^{3}$ cube prepared by $\mathrm{Ga}^{+}$FIB (analysis 5) and $100 \mu \mathrm{m}^{3}$ cube prepared by $\mathrm{Xe}^{+}$ pFIB (analysis 9), which yield $\mathrm{U}-\mathrm{Pb}$ ages with $5.1 \%$ and $6.2 \%$ discordance, respectively. Plotting all data, with the exception of the most discordant datum, on a concordia diagram $(n=10)$ produces a discordant array with intercepts of $2060.20 \pm 0.91$ and $-5 \pm 36 \mathrm{Ma}(\mathrm{MSWD}=0.99)$, while all $\mathrm{Ga}^{+}$and $\mathrm{Xe}^{+}$FIB-TIMS data points $(n=7)$ produce intercepts of $2062.8 \pm 5.8$ and $80 \pm 150 \mathrm{Ma}(\mathrm{MSWD}=3.6)$ and a weighted mean ${ }^{207} \mathrm{~Pb} /{ }^{206} \mathrm{~Pb}$ age of $2060.0 \pm 2.1 \mathrm{Ma}$ (MSWD $=4)$. 

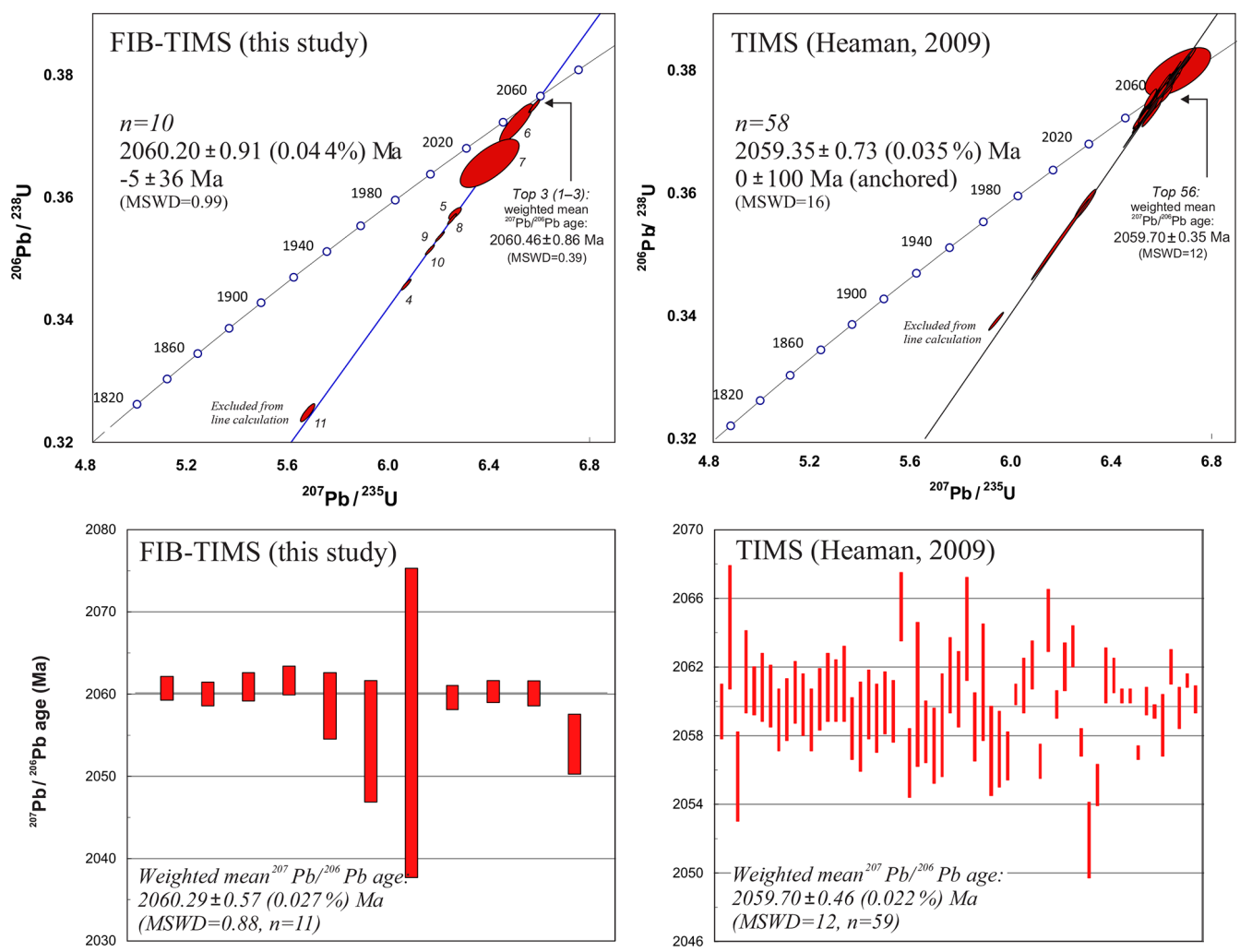

Figure 3. $\mathrm{U}-\mathrm{Pb}$ concordia diagrams and weighted average $\mathrm{Pb} / \mathrm{Pb}$ ages for data generated by FIB-TIMS and TIMS analysis of the Phalaborwa baddeleyite reference material within this study (left). For comparison, all $\mathrm{U} / \mathrm{Pb}$ and $\mathrm{Pb} / \mathrm{Pb}$ data reported by Heaman (2009) are also presented (right), highlighting the natural discordance and variation within the Phalaborwa baddeleyite population. Individual data points are numbered in reference to Table 1 .

\section{Discussion}

\subsection{FIB extraction for $\mathrm{U}-\mathrm{Pb}$ isotopic analysis}

The effects of both the $\mathrm{Ga}^{+}$and $\mathrm{Xe}^{+}$FIB instruments on the $\mathrm{U}-\mathrm{Pb}$ isotope systematics in accessory phase geochronometers has never been explored, and thus the potential for the ion beam to induce $\mathrm{Pb}$ diffusion and loss in exposed surface areas must be addressed for the FIB-TIMS technique. Previous studies utilizing the extraction of baddeleyite domains using FIB instruments (such as for structural and isotopic analysis by atom probe tomography - APT; Reinhard et al., 2017; White et al., 2017a, b) provide a poor comparison, given the application of a low-energy $(\sim 40 \mathrm{pA}, 5 \mathrm{kV})$ final polish to remove material that may have been damaged or implanted with $\mathrm{Ga}$ ions during interaction with the beam. While our new FIB-TIMS data are up to $13.6 \%$ discordant, there is no obvious correlation between the severity of discordance and the method used to isolate the domain for TIMS dating. For example, domains physically broken away from the mount (e.g. with no exposure to either the $\mathrm{Xe}^{+}$or $\mathrm{Ga}^{+}$FIB beam) have ${ }^{206} \mathrm{~Pb} /{ }^{238} \mathrm{U}$ ages of $2052 \pm 4 \mathrm{Ma}$ and $1912 \pm 3.4 \mathrm{Ma}$ (analyses 3-4, Table 1), representing the oldest and secondyoungest measured age of the large Phalaborwa crystal in- corporated into this study. The lack of correlation between measured discordance, FIB ion source $\left(\mathrm{Ga}^{+}\right.$or Xe $\left.{ }^{+}\right)$, FIB exposure time, and subsampled domain size (Fig. 4) provides strong evidence that the extracted domains represent natural heterogeneity of the large Phalaborwa crystal and not localized FIB-induced mobilization and loss of $\mathrm{Pb}$ or other effects related to implantation of the primary ion beam. This observation supports previous studies of FIB-induced damage in materials, which despite inducing up to $22 \mathrm{~nm}$ of surface amortization has never been reported to induce local isotopic or elemental fractionation in the target material (Schaffer et al., 2012; Burnett et al., 2016). Furthermore, the FIBTIMS method had not led to significantly higher procedural $\mathrm{Pb}$ blanks compared to standard chemistry, further supporting the ability of FIB instruments to produce TIMS samples free of contamination and localized elemental fractionation.

\subsection{Isotopic heterogeneity in Phalaborwa baddeleyite}

Single-shot laser ablation inductively coupled plasma mass spectrometry (SS-LA-ICP-MS) work on Phalaborwa has revealed discrepancy from measured TIMS $\mathrm{Pb} / \mathrm{Pb}$ ages of between $0.1 \%$ and $2.6 \%$ and discordance in $\mathrm{U}-\mathrm{Pb}$ systematics of up to $13.7 \%$ (Ibanez-Mejia et al., 2014). Sub-micrometre- 


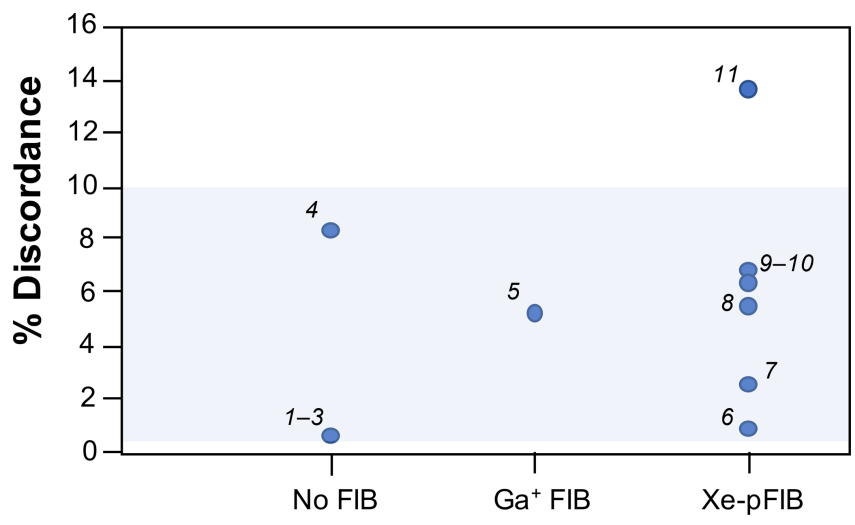

Figure 4. Percentage discordance plotted against extraction method. Discordance reported by Heaman (2009), is shown by the transparent box, and individual data points are numbered in reference to Table 1.

scale variations in the ${ }^{206} \mathrm{~Pb} /{ }^{238} \mathrm{U}$ ratio have also been reported by atom probe analyses of Phalaborwa baddeleyite (White et al., 2017b; Reinhard et al., 2017). ${ }^{206} \mathrm{~Pb} /{ }^{238} \mathrm{U}$ ages generated by SS-LA-ICP-MS (Ibanez-Mejia et al., 2014) hint at variations in age of the Phalaborwa baddeleyite reference material, though the low precision of these data points $(<8.6 \%)$ may partially mask local heterogeneities. By subsampling a single large grain of Phalaborwa baddeleyite, we observe that measured $\mathrm{U}-\mathrm{Pb}$ ages vary by up to $227 \mathrm{Ma}$, and $\mathrm{Pb} / \mathrm{Pb}$ ages vary by less than $6 \mathrm{Ma}$. It is likely that the small volumes analysed by FIB-TIMS (and secondary ionization mass spectrometry - SIMS; c. $10 \times 10 \times 1 \mu \mathrm{m})$ act to subsample natural $\mathrm{U}$ zonation and variation within the Phalaborwa baddeleyite standard that are otherwise homogenized during larger-volume analyses (e.g. whole-grain TIMS or LA-ICPMS). Care must be taken to select pristine subdomains of material when using the Phalaborwa baddeleyite as a smallvolume $\mathrm{U}-\mathrm{Pb}$ mineral standard, particularly for techniques such as FIB-TIMS or atom probe tomography (Reinhard et al., 2017).

An additional possible source of discordance in baddeleyite U-Pb TIMS analysis is the incorporation of zircon overgrowths (which are subjected to Pb loss; Davidson and van Breeman, 1988; Rioux et al., 2010; Pietrzak-Renaud and Davis, 2014) or surrounding common-Pb-bearing phases in the extracted volume. This is not an issue in FIB-TIMS as such features can be removed using the FIB instrument prior to $\mathrm{U}-\mathrm{Pb}$ analysis (Fig. 5). While such work will significantly improve the concordance of generated $\mathrm{U}-\mathrm{Pb}$ ages, it will also reduce the volume of material than can be analysed by TIMS, potentially increasing the risk of grain loss during extraction and manipulation.

\subsection{Minimum sample sizes accessible by FIB-TIMS}

With the development of the $\mathrm{Xe}^{+} \mathrm{pFIB}$, the FIB-TIMS technique can be applied to in situ target mineral grains up to millimetres in size (e.g. Burnett et al., 2016). It is also possible to isolate domains as small as $\sim 5 \mu \mathrm{m}$, though manipulating such small regions under optical microscope (e.g. for acid dissolution prior to ID-TIMS) is challenging and can result in the loss of extracted grains. At the smallest grain sizes, ejection of daughter $\mathrm{Pb}$ atoms from crystal surfaces through direct alpha recoil ejection can result in discordant $\mathrm{U}-\mathrm{Pb}$ ages from the outermost $24 \mathrm{~nm}( \pm 7 \mathrm{~nm})$ of the baddeleyite crystal (Davis and Davis, 2017). This would only become an issue when sampling small grains ( $<15 \mu \mathrm{m}$ thick) in their entirety, as the large surface-area to volume ratio would potentially lead to slightly discordant $\mathrm{U}-\mathrm{Pb}$ ages following extensive ejection of daughter isotopes (Romer, 2003), requiring a simple linear correction on the order of $0.1 \%-0.5 \%$ (Davis and Davis, 2017). Subsampling internal domains of larger grains will circumvent this issue, allowing the targeted extraction of centralized regions which are unlikely to have ejected $\mathrm{Pb}$ during an alpha recoil event.

At the smallest sample sizes, uncertainties will naturally start to increase due to the reduced atoms/counts of $\mathrm{U}$ and $\mathrm{Pb}$. However, we demonstrate that even in the smallest baddeleyite domains analysed here $(0.05 \mu \mathrm{g} ; \sim 10 \mu \mathrm{m}$ length $)$ uncertainties in the corrected ${ }^{206} \mathrm{~Pb} /{ }^{238} \mathrm{U}$ ages do not rise above $\pm 0.85 \%$. Associated ${ }^{207} \mathrm{~Pb} /{ }^{206} \mathrm{~Pb}$ ages display $\pm 0.38 \% 2 \sigma$ uncertainties. The FIB-TIMS technique also acts to circumvent any variability in measured $\mathrm{U}-\mathrm{Pb}$ ratios $(<5 \%)$ induced by orientation-dependent $\mathrm{Pb} / \mathrm{U}$ fractionation during secondary-ion mass spectrometry (Wingate and Compston, 2000; Schmitt et al., 2010) as the high energy of the FIB instrument $(\sim 2.5 \mu \mathrm{A})$ would not induce preferential channelling of ions along low-index crystal lattice orientations, comparable to laser ablation inductively coupled plasma mass spectrometry analysis (Ibanez-Mejia et al., 2014).

\section{Conclusions}

We have shown that volumes as small as $\sim 5 \times 15 \mu \mathrm{m}$ can be effectively isolated, extracted, and dated in situ using the FIB-TIMS technique developed for this study. From these tiny domains, an accurate upper-intercept $\mathrm{U}-\mathrm{Pb}$ age $(2060.2 \pm 0.91 \mathrm{Ma}, 2 \sigma)$ and weighted average $\mathrm{Pb} / \mathrm{Pb}$ age $(2060.29 \pm 0.57 \mathrm{Ma} 2 \sigma)$ can be generated. Both $\mathrm{Ga}^{+}$- and $\mathrm{Xe}^{+}$-source focused ion beams were employed, and while we find no evidence of isotopic fractionation within the target material using either instrument, we recommend using a $\mathrm{Xe}^{+}$pFIB where possible due to the order-of-magnitude faster mill rates, particularly if applying this technique to larger $(>50 \mu \mathrm{m})$ mineral grains and subdomains. Using the FIB-TIMS technique, it is now possible to produce highprecision ages from mineral grains that have been extensively imaged and characterized within a thin section, though ex- 

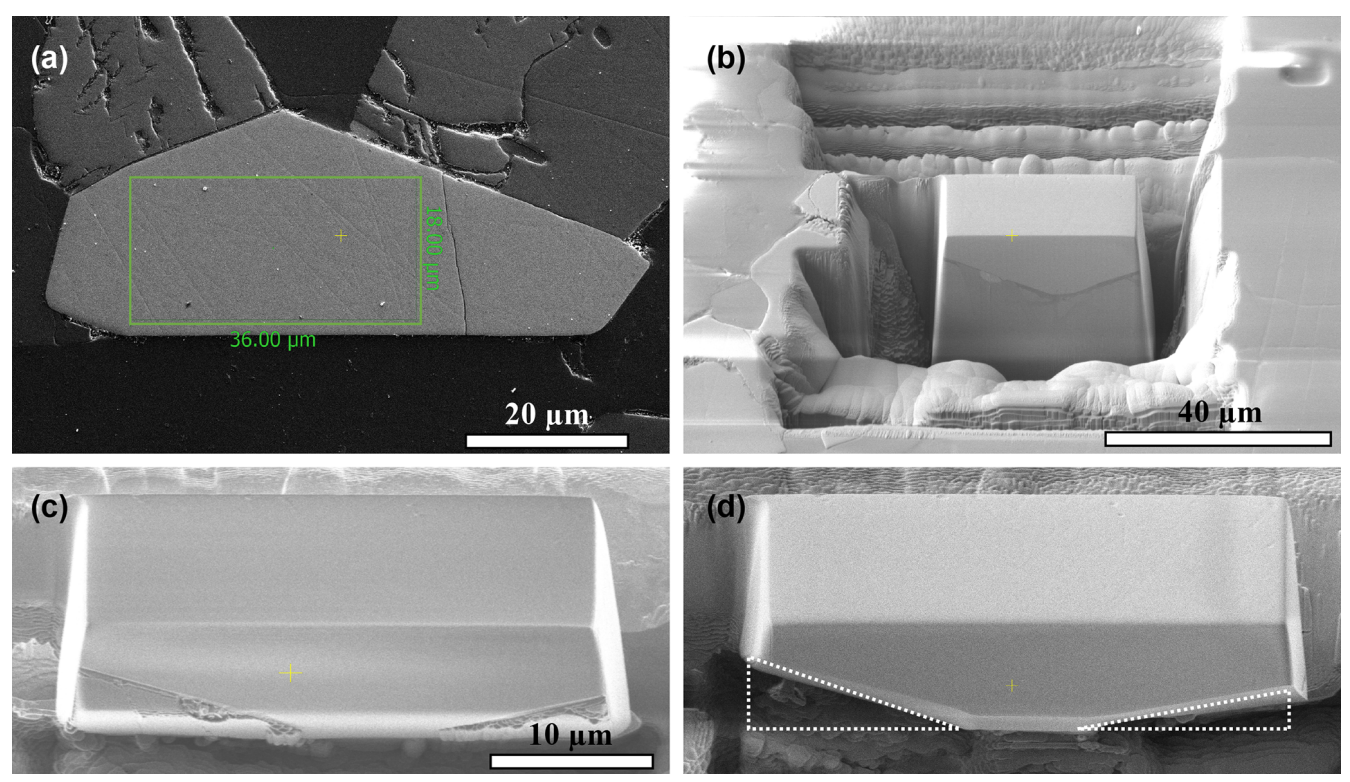

Figure 5. $\mathrm{Xe}^{+}$pFIB images detailing the extraction of a $36 \times 18 \mu \mathrm{m}$ domain of a large $(50 \mu \mathrm{m})$ baddeleyite grain from a thin section of the Duluth gabbro (a). During large-scale cutting (b), small domains of common-Pb-bearing feldspar remained attached to the target baddeleyite $(\mathbf{c})$, though these were quickly removed using the $\mathrm{Xe}^{+} \mathrm{pFIB}$ instrument through a series of tilted and rotated cuts to produce a single grain with no rim or inclusions (d).

tra care must be taken during the physical extraction of the smallest domains. This technique will be of particular importance for meteoritic and returned samples, which are too valuable to be exposed to the destructive protocol typically required for TIMS analysis and will allow the generation of high-precision age data from accessory phases previously inaccessible to geochronology.

Data availability. All data presented and discussed are provided in the paper. For example, all U-Pb data are presented in Table 1.

Author contributions. LFW and JRD conceived the study. LFW and SLK directed and conducted the experiments. KTT and DEM provided materials. All authors interpreted the data. LFW drafted the paper with input from all coauthors.

Competing interests. The authors declare that they have no conflict of interest.

Acknowledgements. Lee F. White is supported by a Hatch Ltd. postdoctoral fellowship. Desmond E. Moser, Sandra L. Kamo, and Kimberly T. Tait are supported by NSERC Discovery Grants. This study was supported by an STFC grant to James R. Darling (ST/S000291/1). We thank Ian Nicklin, Tanya Kizovski, Ana Černok (ROM), Brian Langelier (McMaster University), and Gabriel Arcuri (Western University) for useful discussions on technique development and implementation. We thank Sal Boccia, Jane Howe
(University of Toronto), and Travis Casagrande (McMaster University) for assistance with and access to the $\mathrm{Ga}^{+}$and $\mathrm{Xe}^{+}$focused ion beam instruments incorporated into the study.

Financial support. This research has been supported by the Science and Technology Facilities Council (grant no. ST/S000291/1).

Review statement. This paper was edited by Brenhin Keller and reviewed by Joshua Davies, Graham Edwards, and one anonymous referee.

\section{References}

Amelin, Y.: Geochronology of the Jack Hills detrital zircons by precise $\mathrm{U}-\mathrm{Pb}$ isotope dilution analysis of crystal fragments, Chem. Geol., 146, 25-38, 1998.

Amelin, Y., Krot, A. N., Hutcheon, I. D., and Ulyanov, A. A.: Lead isotopic ages of chondrules and calcium-aluminium-rich inclusions, Science, 80, 1678-1683, 2002.

Barboni, M., Boehnke, P., Keller, B., Kohl, I. E., Schoene, B., Young, E. D., and McKeegan, K. D.: Early formation of the Moon 4.51 billion years ago, Sci. Adv., 3, e1602365, https://doi.org/10.1126/sciadv.1602365, 2017.

Bassim, N., Scott, K, and Giannuzzi, L. A.: Recent advances in focused ion beam technology and applications, MRS Bull., 39, 317-325, 2014.

Bouvier, L. C., Costa, M. M., Connelly, J. N., Jensen, N. K., Wielandt, D., Storey, M., Nemchin, A. A., Whitehouse, M. J., Snape, J. F., Bellucci, J. J., Moynier, F., Agranier, A., Gueguen, 
B., Schonbachler, M., and Bizzarro, M.: Evidence for extremely rapid magma ocean crystallization and crust formation on Mars, Nature, 558, 6-11, https://doi.org/10.1038/s41586-018-0222-z, 2018.

Burnett, T. L., Kelley, R., Winiarski, B., Contreras, L., Daly, M., Gholinia, A., Burke, and M. G., and Withers, P. J.: Large volume serial section tomography by Xe Plasma FIB dual beam microscopy, Ultramicroscopy, 161, 119-129, https://doi.org/10.1016/j.ultramic.2015.11.001, 2016.

Cavosie, A. J., Erickson, T. M., Timms NE, Reddy, S. M., Talavera, C., Montalvo, S. D., Pincus, M. R., Gibbon, R. J., and Moser, D.: A terrestrial perspective on using ex situ shocked zircons to date lunar impacts, Geology, 43, 999-1002, https://doi.org/10.1130/G37059.1, 2015.

Darling, J. R., Moser, D. E., Barker, I. R., Tait, K. T., Chamberlain, K. R., Schmitt, A. K., and Hyde, B. C.: Variable microstructural response of baddeleyite to shock metamorphism in young basaltic shergottite NWA 5298 and improved U-Pb dating of Solar System events, Earth Planet. Sc. Lett., 444, 1-12, https://doi.org/10.1016/j.epsl.2016.03.032, 2016.

Davidson, A. and Van Breemen, O.: Baddeleyite-zircon relationships in coronitic metagabbro, Grenville Province, Ontario: implications for geochronology, Contrib. Mineral. Petr., 100, 291299, 1988

Davis, W. J. and Davis, D. W.: Alpha Recoil Loss of Pb from Baddeleyite Evaluated by High Resolution Ion Microprobe (SHRIMP II) Depth Profiling and Numerical Modelling: Implications for the Interpretation of U-Pb Ages in Small Baddeleyite Crystals, in: AGU Geophysical Monograph Series 232: Microstructural Geochronology: Planetary Records Down to Atom Scale, 247259, https://doi.org/10.1002/9781119227250, 2017.

Echlin, M., Mottura, A., Torbet, C., and Pollock, T. M.: A new tribeam system for three dimensional multimodal materials analysis, Rev. Sci. Instrum., 83, 023701, https://doi.org/10.1063/1.3680111, 2012.

Gerstenberger, H. and Haase, G.: A highly effective emitter substance for mass spectrometric $\mathrm{Pb}$ isotope ratio determinations, Chem. Geol., 136, 309-312, 1997.

Gradstein, F. M., Ogg, J. G., Smith, A. G., Bleeker, W., and Lourens, L.: A new geologic time scale, with special reference to Precambrian and Neogene, Episodes, 27, 83-100, 2004.

Heaman, L. M.: The application of U-Pb geochronology to mafic, ultramafic and alkaline rocks: An evaluation of three mineral standards, Chem. Geol., 261, 42-51, https://doi.org/10.1016/j.chemgeo.2008.10.021, 2009.

Heaney, P. J., Vicenzi, E. P., Giannuzzi, L. A., and Livi, K. J. T.: Focused ion beam milling: A method of site-specific sample extraction for microanalysis of Earth and planetary materials, Am. Mineral., 86, 1094-1099, 2001.

Herd, C. D. K., Moser, D. E., Tait, K. T., Darling, J. R., Shaulis, B. J., and McCoy, T. J.: Crystallization of Baddeleyite in Basaltic Rocks from Mars, and Comparisons with the Earth, Moon and Vesta, in: AGU Geophysical Monograph Series 232: Microstructural Geochronology: Planetary Records Down to Atom Scale, 137-166, 2018.

Hiess, J., Condon, D. J., McLean, N., and Noble, S.: ${ }^{238} \mathrm{U} /{ }^{235} \mathrm{U}$ systematics in terrestrial uranium-bearing minerals, Science, 335, 1610-1614, 2012.
Ibanez-Mejia, M., Gehrels, G. E., Ruiz, J., Vervoort, J. D., Eddy, M. P., and $\mathrm{Li}, \mathrm{C} .:$ Small-volume baddeleyite $(\mathrm{ZrO} 2) \mathrm{U}-\mathrm{Pb}$ geochronology and Lu-Hf isotope geochemistry by LA-ICPMS, Techniques and applications, Chem. Geol., 384, 149-167, https://doi.org/10.1016/j.chemgeo.2014.07.011, 2014.

Jaffey, A. H., Flynn, K. F., Glendenin, L. E., Bentley, W. C., and Essling, A. M.: Precision measurement of half-lives and specific activities of ${ }^{235} \mathrm{U}$ and ${ }^{238} \mathrm{U}$, Phys. Rev., 4, 1889-1906, 1971.

Košler, J., Wiedenbeck, M., Wirth, R., Hovorka, J., Sylvester, P., and Míková, J.: Chemical and phase composition of particles produced by laser ablation of silicate glass and zircon - implications for elemental fractionation during ICP-MS analysis, J. Anal. Atom. Spectrom., 20, 402-409, 2005.

Krogh, T. E.: A low contamination method for hydrothermal decomposition of zircon and extraction of $\mathrm{U}$ and $\mathrm{Pb}$ for isotopic age determinations, Geochim. Cosmochim. Ac., 37, 485-494, 1973.

Krogh, T. E.: Improved accuracy of U-Pb zircon ages by the creation of more concordant systems using an air abrasion technique, Geochim. Cosmochim. Ac., 46, 637-649, 1982.

Krogh, T. E., Corfu, F., Davis, D. W., Dunning, G. R., Heaman, L. H., Kamo, S. L., Machado, N., Greenough, J. D., and Nakamura, E.: Precise U-Pb isotopic ages of diabase dykes and mafic to ultramafic rocks using trace amounts of baddeleyite and zircon, in: Mafic dyke swarms, edited by: Halls, H. C. and Fahrig, W. F., Geological Association of Canada Special Paper 34, 147-152, 1987.

Krogh, T. E., Kamo, S. L., and Bohor, B. F.: Fingerprinting the K/T impact site and determining the time of impact by $\mathrm{U}-\mathrm{Pb}$ dating of single shocked zircons from distal ejecta, Earth Planet. Sc. Lett., 119, 425-429, 1993a.

Krogh, T. E., Kamo, S. L., Sharpton, V., Marin, L., and Hildebrand, A. R.: U-Pb ages of single shocked zircons linking distal K/T ejecta to the Chicxulub crater, Nature, 366, 731-733, 1993 b.

Matsui, S., Kaito, T., Fujita, J. I., Komuro, M., Kanda, K., and Haruyama, Y.: Three-dimensional nanostructure fabrication by focused-ion-beam chemical vapor deposition, J. Vac. Sci. Technol B, 18, 3181-3184, 2000.

Moser, D. E., Cupelli, C. L., Barker, I. R., Flowers, R. M., Bowman, J. R., Wooden, J., and Hart, J. R.: New zircon shock phenomena and their use for dating and reconstruction of large impact structures revealed by electron nanobeam (EBSD, CL, EDS) and isotopic $\mathrm{U}-\mathrm{Pb}$ and $(\mathrm{U}-\mathrm{Th}) / \mathrm{He}$ analysis of the Vredefort dome, Can. J. Earth Sci., 48, 117-139, https://doi.org/10.1139/E11-011, 2011.

Moser, D. E., Chamberlain, K. R., Tait, K. T., Schmitt, A. K., Darling, J. R., Barker, I. R., and Hyde, B. C.: Solving the Martian meteorite age conundrum using microbaddeleyite and launch-generated zircon, Nature, 499, 454-457, https://doi.org/10.1038/nature12341, 2013.

Paquette, J.-L., Goncalves, P., Devouard, B., and Nicollet, C.: Micro-drilling ID-TIMS U-Pb dating of single monazites: A new method to unravel complex poly-metamorphic evolutions. Application to the UHT granulites of Andriamena (North-Central Madagascar), Contrib. Mineral Petr., 147, 110-122, 2004.

Parrish, R. R. and Noble, S. R.: Zircon U-Th-Pb Geochronology by Isotope Dilution - Thermal Ionization Mass Spectrometry (IDTIMS), in: Reviews in Mineralogy and Geochemistry: Zircon, edited by: Hanchar, J. M. and Hoskin, P. W. O., Mineralogical Society of America, Washington DC, 183-213, 2003. 
Pietrzak-Renaud, N. and Davis, D.: U-Pb geochronology of baddeleyite from the Belleview metadiabase: Age and geotectonic implications for the Negaunee Iron Formation, Michigan, Precambrian Res., 250, 1-5, 2014.

Reddy, S. M., van Riessen, A., Saxey, D. W., Johnson, T. E., Rickard, W., Fougerouse, D., Fischer, S., Prosa, T. J., Rice, K. P., Reinhard, D. A., Chen, Y., and Olson, D.: Mechanisms of deformation-induced trace element migration in zircon resolved by atom probe and correlative microscopy, Geochim. Cosmochim. Ac., 195, 158-170, https://doi.org/10.1016/j.gca.2016.09.019, 2016.

Reinhard, D. A., Moser, D. E., Martin, I., Rice, K. P., Chen, Y., Olson, D., Lawrence, D., Prosa, T. J., and Larson, D. J.: Atom Probe Tomography of Phalaborwa Baddeleyite and Reference Zircon BR266, in: AGU Monograph: Microstructural Geochronology: Planetary Records Down to Atom Scale, 315326, https://doi.org/10.1002/9781119227250, 2017.

Reischmann, T.: Precise $\mathrm{U} / \mathrm{Pb}$ age determination with baddeleyite ( $\mathrm{ZrO} 2)$, a case study from the Phalaborwa igneous complex, South Africa, South African J. Geol., 98, 1-4, 1995.

Rioux, M., Bowring, S., Dudás, F., and Hanson, R.: Characterizing the U-Pb systematics of baddeleyite through chemical abrasion: application of multi-step digestion methods to baddeleyite geochronology, Contrib. Mineral. Petr., 160, 777-801, 2010.

Romer, R. L.: Alpha-recoil in U-Pb geochronology: Effective sample size matters, Contrib. Mineral. Petr., 145, 481-491, 2003.

Schaffer, M., Schaffer, B., and Ramasse, Q.: Sample preparation for atomic-resolution STEM at low voltages by FIB, Ultramicroscopy, 114, 62-71, 2012.

Schmitt, A. K., Chamberlain, K. R., Swapp, S. M., and Harrison, T. M.: In situ U-Pb dating of micro-baddeleyite by secondary ion mass spectrometry, Chem. Geol., 269, 386-395, https://doi.org/10.1016/j.chemgeo.2009.10.013, 2010.
Smith, N. S., Skoczylas, W. P., Kellogg, S. M., Kinion, D. E., and Tesch, P. P.: High brightness inductively coupled plasma source for high current focused ion beam applications, J. Vac. Sci. Technol. B, 24, 2902-2906, 2006.

Söderlund, U. and Johansson, L.: A simple way to extract baddeleyite $\left(\mathrm{ZrO}_{2}\right)$, Geochem. Geophy. Geosy., 3, 1014, https://doi.org/10.1029/2001gc000212, 2002.

Stacey, J. S. and Kramers, J. D.: Approximation of terrestrial lead isotope evolution by a two-stage model, Earth Planet. Sc. Lett., 26, 207-221, 1975.

White, L. F., Darling, J. R., Moser, D. E., Reinhard, D. A., Dunlop, J., Larson, D. J., Lawrence, D., and Martin, I.: Complex nanostructures in shocked, annealed and metamorphosed baddeleyite defined by atom probe tomography, in: AGU Geophysical Monograph Series 232: Microstructural Geochronology: Planetary Records Down to Atom Scale, edited by: Moser, D. E., Corfu, F., Darling, J. R., Reddy, S. M., and Tait, K., John Wiley \& Sons, Inc, Hoboken, NJ, 2017a.

White, L. F., Darling, J. R., Moser, D. E., Reinhard, D. A., Prosa, T. J., Bullen, D., Olson, D., Larson, D., and Martin, I.: Atomic scale age resolution of planetary events, Nat Commun., 6 pp., https://doi.org/10.1038/ncomms15597, 2017b.

Wingate, M. T. D. and Compston, W.: Crystal orientation effects during ion microprobe $\mathrm{U}-\mathrm{Pb}$ analysis of baddeleyite, Chem. Geol., 168, 75-97, 2000.

Yuan, X., Wehrs, J., Ma, H., Al-Samman, T., Korte-Kerzel, S., Goken, M., Michler, J., Spolenak, R., and Wheeler, J. M.: Investigation of the deformation behaviour of aluminium micropillars produced by focused ion beam machining using $\mathrm{Ga}$ and Xe ions, Scripta Materialia, 127, 191-194, 2017.

Ziegler, J. F., Biersack, J. P., and Littmark, U.: The stopping range of ions in matter, New York, USA, 1985. 